

\title{
Prevalence of job burnout syndrome and its influential factors among military personnel
}

Salman Zarei ${ }^{1}$, Parviz Dabaghi ${ }^{2}$

\author{
Journal of Research \& Health \\ Social Development \& Health Promotion \\ Research Center \\ Vol. 9, No.1, Jan \& Feb 2019 \\ Pages: $45-52$ \\ DOI: $10.29252 / j r h .9 \cdot 1.45$ \\ Original Article
}

1. Correspondence to: Department of Psychology, Faculty of Counseling, Lorestan Universitty, Khorramabad, Iran

Email: salman_zarei@yahoo.com

2. Department of Psychologhy, Faculty of

Clinical Psychology, Aja Universitty of

Medical Sciences, Tehran, Iran

Received: 6 Jun 2017

Accepted: 2 Jan 2018

How to cite this article: Zarei S, Dabaghi P. Prevalence of job burnout syndrome and its influential factors among military personnel. $J$ Research \& Health2019; 9(1): 45- 52.

\begin{abstract}
Job burnout can reduce job performance. The present study aimed to investigate the job burnout syndrome and its effective factors among military personnel. In this cross-sectional study, 930 military personnel from different areas were selected via cluster sampling. For data collection, the job burnout questionnaire and the job description index were used. The findings showed that 33.8 percent of the personnel were at a low level, 46.5 at a moderate level, and 19.7 percent at an intense level of emotional exhaustion. Considering depersonalization dimension, 51.7 percent were at low level, 37.7 at the moderate level, and 10.5 percent at an intense level. Finally, regarding the lack of personal accomplishment, 47.8 percent were at low level, 31.1 at the moderate level, and 21.1 percent at an intense level. The results of MANOVA showed a significant difference with respect to job burnout among the personnel based on demographic characteristics. Finally, the results revealed a significant relationship between job description index, job burnout, and its components. Accordingly, managers and authorities are suggested to pay more attention to the effective factors influencing job burnout among military personnel.
\end{abstract}

Keywords: Job, Burnout, Military, Satisfaction

\section{Introduction}

Job burnout has become an endemic organizational problem today. Job burnout is linked with numerous problems for both afflicted persons and organizations in which the afflicted individuals work. Job burnout is essentially a psychological syndrome due to chronic emotional and interpersonal stressors experienced by individuals at work. This syndrome then dictates the individuals' responses to their work, organizations, coworkers, and themselves [1,2]. Job burnout is a prominent problem that is plaguing current organizations [3]. Job burnout is typically understood to be a three-dimensional construct consisting of components, emotional exhaustion, depersonalization, and reduced personal accomplishment. Emotional exhaustion refers to the phenomenon of depletion of one's emotional resources, while depersonalization refers to a negative attitude toward other people or the job itself. Reduced personal accomplishment refers to a decrease in feelings of job competence and productivity [4]. However, reduced personal accomplishment has received criticism by researchers as it is overly similar to selfefficacy [5] and it correlates weakly with the two other burnout components, as well as with common burnout [4].

Depersonalization may be considered as 
the core components of burnout [3]. Scholars suggest that burnout has a negative relationship with work engagement [6]. Burnout has been linked to depression [7], as well as higher rates of absenteeism, reduced well-being, and poor performance [8]. Burnout has negative consequences for both afflicted persons and the organizations in which those persons work [9]. The resultant aftermath of burnout is lost productivity and the significant expense of recruiting and training new employees makes understanding of burnout an issue of critical significance. Research into the antecedents of burnout is usually divided into three categories: organizational, occupational, and individual $[5,10,11]$. Organizational psychological environments and scarcity of resources coupled with increases in performance expectations and demographic factors contribute to burnout $[5,12]$. Other organizational and individual factors include job demands, job resources, self-esteem, and self-determination $[13,14]$. In addition, many prominent researchers have linked job burnout with numerous problems: domestic violence [15], poor physical activity [16], poor eating habits [17], poor emotional health [18], excessive drinking [16], substance abuse [19], decreased marital satisfaction [20], decreased emotional wellbeing [21], and neuroticism [22].

In addition, studies have shown that the major cause of burnout is job stress [23]. Occupational stress may be due to poor working conditions, including workload (high or low) or quality (being outside the person's abilities), lack of fitness, lack of job security, unfulfilled career ambitions, and improper relationship with employees, ambiguity, and role conflict [24]. Maslach counts some organizational factors effective in the incidence of burnout that include corporate communications, the monotony of work, and decision-making involvement [25]. Stress is in the lives of all employed people. Career changes, like changes in salary, job promotions, reductions or increases in staffing, and social changes, are topics that somehow distress people and cause confusion, worry, and anxiety [26]. On the other hand, careers such as military create more stress due to the nature and responsibilities of this job. Military employees encounter a variety of problems according to the job they have. According to the above-mentioned issues, studying burnout in employees of organizations and discovering its various related factors seems essential in order to prevent Job Burnout. Altogether, employment is an important source of livelihood and social status that can also lead to resentment and undermining physical and mental powers. Workplace consists of physical, mental, social, and organizational motivations, all of which can be a cause of stress. Occupations such as military work bring a lot of stress, which is due to the nature, type, functions, and responsibilities of these jobs and burnout can be mentioned as one of the results of excessive and prolonged stress in the military workplace. In addition, two important factors in the organizational management are humans and operational systems of the organization. Since the operational systems come into force by men, it can be argued that the most important asset of the organization is human resources. Now, administrators are aware that they can guarantee their success and efficiency by investing in human resources. Considering the basic needs of our society to militaries, administrators should pay more attention to problems and needs of their staff in order to reach a better capability, prevent burnout, and increase motivation to work. Therefore, the aim of the present study was to evaluate the prevalence of job burnout syndrome and its effective factors among military personnel.

\section{Method}

This research is a cross-sectional study. The research population included military personnel of Iranian Army in 2016. In total, 930 military personnel from different areas were selected via cluster sampling. The participants comprised 186 persons (20\%) from Bandar Abbas, the south of Iran (Persian Golf), 180 persons (19.4 percent) from Bushehr, 144 persons (15.5 percent) 
from Konarak, 140 persons (15.1 percent) from Jask, 142 persons (15.3\%) from Rasht, and 138 people (14.8 percent) from Anzali. To gather data for this study, three questionnaires, Maslach Burnout Inventory (MBI), Job Description Index (JDI), and a demographic questionnaire were used.

Maslach Burnout Inventory: Job burnout was measured by using the MBI [27]. The scale measures the three dimensions, emotional exhaustion, depersonalization, and reduced personal accomplishment. The questionnaire contains 22 items and uses a seven-point scale ranging from one (completely disagree) to seven (completely agree). The Cronbach's alpha of emotional exhaustion, depersonalization, and reduced personal accomplishment was 0.862 , 0.745 , and 0.792 , respectively [15].

Job Description Index: The JDI was designed to measure the construct of job satisfaction, developed by Smith, Kendall, and Hulin [28]. This questionnaire contains 30 items and includes five subscales: 1) satisfaction with job, 2) satisfaction with pay, 3) satisfaction with supervision, 4) satisfaction with promotion and 5) satisfaction with co-workers. This questionnaire uses a five-point scale ranging from one (strongly disagree) to five (strongly agree). The minimum and maximum scores are 30 and 150, respectively, and a high score indicates high job satisfaction. It is noteworthy that in Dunham, Smith, Blackburn's research, the split-half reliability coefficient was 0.84 for the satisfaction with job subscale, 0.70 for the satisfaction with pay subscale, 0.87 for the satisfaction with supervision subscale, 0.79 for the satisfaction with promotion subscale, and 0.88 for the satisfaction with co-worker subscale [29].

Demographic Questionnaire: This researchermade questionnaire included demographic information such as level of education, job experience, and mission experience. As mentioned before, occupations such as military work bring a lot of stress, which is due to nature, type, functions, and responsibilities in these jobs. Therefore, based on a literature review $[5,10,11]$ in this study, the researcher selected the mentioned demographic information because of their importance and potential to decrease or increase the job burnout syndrome.

\section{Results}

The demographic characteristics of the personnel are presented in Table 1 .

Table 1 Frequency of employees based on demographic characteristics

\begin{tabular}{lcc}
\hline & Demographic Specification & $\mathrm{n}(\%)$ \\
\hline \multirow{2}{*}{ Education level } & Diploma & $533(59.5)$ \\
& Associate degree & $140(11.2)$ \\
& Bachelor of science & $273(29.3)$ \\
\hline \multirow{3}{*}{ Job experience } & First decade & $475(49.1)$ \\
& Second decade & $363(39.1)$ \\
& Third decade & $110(11.8)$ \\
\hline \multirow{3}{*}{ Mission experience } & Less than 5 times & $194(20.2)$ \\
& Between 6 and 10 times & $201(21.6)$ \\
& Between 11 and 15 times & $134(14.4)$ \\
& Between 16 and 20 times & $333(35.8)$ \\
\hline
\end{tabular}

Table 2 Frequency of intensity of job burnout among the personnel

\begin{tabular}{lccc}
\hline Intensity & Low & Moderate & High \\
\hline Variable & $\mathrm{n}(\%)$ & $\mathrm{n}(\%)$ & $\mathrm{n}(\%)$ \\
Emotional exhaustion & $314(33.8)$ & $433(46.5)$ & $183(19.7)$ \\
Depersonalization & $480(51.7)$ & $352(37.8)$ & $98(10.5)$ \\
Reduced personal accomplishment & $445(47.8)$ & $289(31.1)$ & $196(21.1)$ \\
\hline
\end{tabular}


The results in Table 2 show that majority of the personnel were at a moderate level in terms of emotional exhaustion $(46.5 \%)$, at a low level in terms of depersonalization $(51.7 \%)$, and at a low level in terms of reduced personal accomplishment (47.8\%).

Table 3 Determination of the relationship between job burnout and demographic characteristics (MANOVA)

\begin{tabular}{|c|c|c|c|c|c|c|c|}
\hline \multicolumn{2}{|c|}{ Demographics } & \multicolumn{2}{|c|}{$\begin{array}{l}\text { Emotional } \\
\text { exhaustion }\end{array}$} & \multicolumn{2}{|c|}{ Depersonalization } & \multicolumn{2}{|c|}{$\begin{array}{l}\text { Reduced personal } \\
\text { accomplishment }\end{array}$} \\
\hline & & Mean & $\mathrm{p}$-value & Mean & p-value & Mean & p-value \\
\hline \multirow{3}{*}{ Education level } & Diploma & 27.06 & \multirow{3}{*}{0.031} & 8.53 & \multirow{3}{*}{0.082} & 29.66 & \multirow{3}{*}{0.711} \\
\hline & $\begin{array}{l}\text { Associate } \\
\text { degree }\end{array}$ & 23.55 & & 7.67 & & 30.06 & \\
\hline & $\begin{array}{l}\text { Bachelor of } \\
\text { science }\end{array}$ & 25.57 & & 8.08 & & 29.33 & \\
\hline \multirow{3}{*}{ Job experience } & $\begin{array}{l}\text { First } \\
\text { decade }\end{array}$ & 27.52 & \multirow{3}{*}{0.003} & 7.43 & \multirow{3}{*}{0.21} & 29.66 & \multirow{3}{*}{0.087} \\
\hline & Second decade & 26.01 & & 7.25 & & 30.27 & \\
\hline & Third decade & 29.73 & & 8.02 & & 29.61 & \\
\hline \multirow{5}{*}{$\begin{array}{l}\text { Mission } \\
\text { experience }\end{array}$} & $\begin{array}{l}\text { Less than } 5 \\
\text { times }\end{array}$ & 25.90 & \multirow{5}{*}{0.098} & 7.80 & \multirow{4}{*}{0.057} & 29.19 & \multirow{5}{*}{0.329} \\
\hline & $\begin{array}{l}\text { Between } 6 \text { and } \\
10 \text { times }\end{array}$ & 25.11 & & 8.08 & & 29.81 & \\
\hline & $\begin{array}{l}\text { Between } 11 \text { and } \\
15 \text { times }\end{array}$ & 25.23 & & 8.18 & & 30.36 & \\
\hline & $\begin{array}{l}\text { Between } 16 \text { and } \\
20 \text { times }\end{array}$ & 26.16 & & 8.42 & & 29.91 & \\
\hline & $\begin{array}{l}\text { More than } 20 \\
\text { times }\end{array}$ & 26.57 & & 8.51 & & 30.37 & \\
\hline
\end{tabular}

The results in Table 3 show that there is a significant relationship between emotional exhaustion and education level $(\mathrm{p}<0.05)$. Therefore, emotional exhaustion was higher in militaries with a diploma degree compared to other groups. According to Table 3, there is a significant relationship between depersonalization and education level $(p<0.01)$. Therefore, depersonalization in those serving in their third decade was higher compared to other groups. Finally, according to Table 3, there is no significant relationship between reduced personal accomplishment and education level $(\mathrm{p}<0.05)$.

\begin{tabular}{|c|c|c|c|c|c|c|c|c|}
\hline Variables & 1 & 2 & 3 & 4 & 5 & 6 & 7 & 8 \\
\hline 1. Emotional exhaustion & 1 & & & & & & & \\
\hline 2. Depersonalization & $0.32 * *$ & 1 & & & & & & \\
\hline $\begin{array}{l}\text { 3. Reduced personal } \\
\text { accomplishment }\end{array}$ & $-0.21 * *$ & $-0.18^{*}$ & 1 & & & & & \\
\hline 4. Satisfaction with job & $-0.11 *$ & $-0.12 *$ & $0.15^{*}$ & 1 & & & & \\
\hline 5. Satisfaction with pay & $-0.19^{*}$ & -0.08 & $0.12 *$ & $0.32 * *$ & 1 & & & \\
\hline 6. Satisfaction with supervision & $-0.16^{*}$ & -0.07 & $0.11^{*}$ & $0.40 * *$ & $0.47 * *$ & 1 & & \\
\hline 7. Satisfaction with promotion & $-0.15^{*}$ & -0.09 & $0.16^{*}$ & $0.46^{* *}$ & $0.56^{* *}$ & $0.48 * *$ & 1 & \\
\hline 8. Satisfaction with co-workers & $-0.12 *$ & $-0.14 *$ & $0.13 *$ & $0.48 * *$ & $0.50 * *$ & $0.54 * *$ & $0.57 * *$ & 1 \\
\hline
\end{tabular}

The results of pearson correlation analyz (Table 4) showed emotional exhaustion had a significant negative correlation with all variables of job descriptionindex $(p<0.05)$. In addition, the results showed that depersonalization had a significant negative correlation with satisfaction with job $(\mathrm{r}=-0.12, \mathrm{p}<0.05)$ and satisfaction with coworkers $(r=-0.14, p<0.05)$. Finlay, the results of the analysis of Pearson Correlation showed that reduced personal accomplishment had a 
significant positive correlation with all variables

of job description index $(\mathrm{p}<0.05)$.

Table 5 Regression coefficient

\begin{tabular}{lcccc}
\hline Criteria variables & Prediction variables & $\beta$ & $\mathrm{T}$ & $\mathrm{p}$-value \\
\hline \multirow{4}{*}{ Emotional } & Satisfaction with job & -0.29 & -2.62 & 0.009 \\
exhaustion & Satisfaction with pay & -0.21 & -2.29 & 0.022 \\
& Satisfaction with supervision & -0.25 & -2.40 & 0.016 \\
& Satisfaction with promotion & -0.19 & -2.16 & 0.031 \\
& Satisfaction with co-workers & -0.16 & -1.96 & 0.049 \\
\hline \multirow{5}{*}{ Depersonalization } & Satisfaction with job & -0.28 & -3.23 & 0.001 \\
& Satisfaction with pay & -0.02 & -0.013 & 0.621 \\
& Satisfaction with supervision & -0.084 & -0.023 & 0.248 \\
& Satisfaction with promotion & -0.098 & -1.34 & 0.178 \\
& Satisfaction with co-workers & -0.25 & -3.36 & .0 .001 \\
\hline \multirow{5}{*}{ Reduced personal } & Satisfaction with job & 0.12 & 2.46 & 0.04 \\
& Satisfaction with pay & 0.07 & 0.948 & 0.344 \\
& Satisfaction with supervision & 0.026 & 0.104 & 0.917 \\
& Satisfaction with promotion & 0.068 & 0.218 & 0.824 \\
& Satisfaction with co-workers & 0.022 & 0.245 & 0.807 \\
\hline
\end{tabular}

The results of ENTER regression analysis in Table 5 show that satisfaction with job $(\beta=$ $-0.29, p<0.01)$, satisfaction with pay $(\beta=-0.21$, $\mathrm{p}<0.05)$, satisfaction with supervision $(\beta=$ $-0.25, p<0.05)$, satisfaction with promotion $(\beta=$ $-0.19, p<0.05)$, and satisfaction with co-workers $(\beta=-0.16, p<0.05)$ could predict emotional exhaustion. Also, the results of ENTER regression analysis showed that satisfaction with the job $(\beta=-0.28, p<0.01)$ and satisfaction with co-workers $(\beta=-0.25, p<0.01)$ could predict depersonalization. Finally, the results of ENTER regression analysis showed that satisfaction with the job $(\beta=0.12, p<0.05)$ could predict reduced personal accomplishment.

\section{Discussion}

The aim of the present study was to investigate job burnout syndrome and its effective factors among military personnel. In terms of emotional exhaustion, $33.8 \%$ of the personnel were assessed to be at a low level, $46.5 \%$ at a moderate level and $19.7 \%$ at a high level. According to the definition of Maslach and Jackson, emotional exhaustion is "a sense of compression and loss of a person's emotional resources" [27]. Emotional exhaustion leads to the loss of individual emotional energy and makes that person lose his/her motivation to act and do something boring. When symptoms of emotional exhaustion appear, the person has the feeling of helplessness and since the military personnel is exposed to numerous stressors due to the nature of their job [30], the work environment eventually drains the emotional and psychological resources, thus leading to burnout syndrome [10].

In other words, due to the military personnel exposure to stressful situations such as longterm mission, they are faced with emotional exhaustion and their ability reduces. Thus, empowering military personnel to cope with stressful factors alongside providing conditions for reduction and elimination of these factors can create a relaxed working environment and increase the capacity and efficiency of military personnel and reduce their level of emotional exhaustion. In terms of depersonalization, $51.7 \%$ of nurses were at a low level, $37.8 \%$ at a moderate level, and $10.5 \%$ at a high level of depersonalization. This burnout dimension is related to non-emotional and violent responses of persons to clients, co-workers, and partners. A person with job burnout syndrome has negative emotions and attitudes; he/she blames others and sees people as objects, not human. For example, someone with burnout sees his/her co-workers as an object and 
identifies them with a kind of problems, room number, etc., and no longer communicates with others [31]. According to Dick job, burnout is the severe exhaustion and feeling of being abused such that this type of fatigue cannot be relieved by rest or even vacation [32]. He also believes that job burnout is a state that a person sees him/her less than others and feels that his/ her job and action is not acknowledged [32]. The result of an investigation by Lopez Franco et al. reflected a low level of job burnout that is inconsistent with the results of the present investigation [33]. In addition, in terms of the lack of personal accomplishment, $47.8 \%$ of the military personnel were observed to be at a low level, $31.1 \%$ at a moderate level, and $21.1 \%$ at a high level. In this dimension of job burnout, a person feels his/her performance is without success and in other words, cognitive performance or success is more important than the real success and performance [27]. The results of investigations by Lopez Franco et al. and Adriaenssens, Gucht, and Maes reflected low levels of lack of personal accomplishment that are consistent with the results of the present investigation [30,33]. Based on the research findings, emotional exhaustion has a significant negative correlation with all variables of job description index. In addition, the results showed that depersonalization had a significant negative correlation with satisfaction with job and satisfaction with co-workers. Finlay, the results of the analysis of Pearson Correlation showed that personal accomplishment had a significant positive correlation with all variables of job description index. Finally, the study was limited, as the job burnout questionnaire though validated on Iranian population was not specifically validated on Iranian military personnel. Finally, Based on the results obtained in this survey and the validation of the hypotheses which indicates a negative relationship between the burnout and its components with job satisfaction, the following suggestions are offered: 1) Providing necessary training in the training course of job burnout and ways to deal with it to managers to increase managers' awareness of occupational stress and ways to avoid the stress. 2) Creating a group supports in the organization and providing an honest and effective communication with colleagues can prevent individuals' job burnout. 3) It is recommended to take some substantive measures in fair and equitable payment to the people who are doing something and reduce job burnout and enhance the effectiveness of the organization by improving job satisfaction, satisfaction with work conditions and reducing job pressures. 4) Improving communication networks in the organization so that they can easily express their criticisms, complaints and suggestions without fear to prevent the occurrence of job burnout.

\section{Conclusion}

As stated, burnout is one of the pitfalls of the organization's health that can reduce the efficiency, effectiveness and productivity of the organization, hence addressing it because of the strategic position of the military forces in Islamic Republic of Iran is inevitable. The results of the study about the degree of burnout and its analysis in three dimensions including emotional exhaustion, depersonalization and individual inefficiency, showed that the status of this variable is somewhat acceptable but insurmountable so that neglect of it can put it in an acute and then critical situation, which also leads to a reduction in productivity and the loss of the organization's capacity as a strategic force, because the most important competitive advantage of the organization are healthy and capable human capital. Therefore, in light of the above, it is necessary to take medium-term actions to maintain this variable in an acceptable condition and to convert it into a desirable situation. Also, it should be noted that military forces should precisely pay attention to the changes required in different units due to the nature of their workplace and missions in various geographic, cultural, political and operational settings. Of course, any action taken to eliminate signs and symptoms of job burnout in the staff is in fact a step towards increased productivity. Since people with pre-inflammatory burnout 
have been overwhelmed with high levels of work in their assigned tasks, their return to their current state of affairs helps organizations achieve their goals. Altogether, according to the research findings and in terms of stressful nature of military personnel job, it is necessary that managers and authorities pay attention to the effect of job burnout factor of military personnel, its level, so as to provide solutions in order to avoid or at least decrease its effects and disadvantages. Some implications could focus on the promotion of adequate professional autonomy, creating time- out facilities and provision of counseling for exposed personnel and training them with coping skills.

\section{Acknowledgments}

The authors express their most sincere thanks to the authorities of Iranian Army and all participating employees because of their support and contribution.

\section{Contribution}

Study design: SZ

Data collection and analysis: SZ, PD

Manuscript preparation: SZ

\section{Conflict of Interest}

"The authors declare that they have no competing interests".

\section{Funding}

The author (s) received no financial support for the research, authorship and/or publication of this article.

\section{References}

1- Maslach C, Leiter MP, Jackson SE. Making a significant difference with burnout interventions: researcher and practitioner collaboration. J Organ Behav2012; 33(2): 296-300.

2-Yavas U, Babakus E, Karatepe OM. Does hope moderate the impact of job burnout on frontline bank employees' inrole and extra-role performances? International Journal of Bank Marketing2013; 31(1):56-70.

3- Schaufeli WB. Past performance and future perspectives of burnout research. SA Journal of Industrial Psychology2003; 29(4): 1-15.

4- Purvanova RK, Muros JP. Gender differences in burnout: A meta-analysis. J Vocat Behav2010; 77(2):168-85.
5- Cordes CL, Dougherty TW. A review and an integration of research on job burnout. Acad Manage Rev1993; 18(4): 621-56.

6- Schaufeli WB, Bakker AB. Job demands, job resources and their relationship with burnout and engagement: a multi-sample study. J Organ Behav2004; 25: 293-315.

7- Ahola K, Hakanen J. Job strain, burnout, and depressive symptoms: a prospective study among dentists. J Affect Disord2007; 104(1-3): 103-10.

8- Brummelhuis LL, Van Der Lippe T, Kluwer ES, Flap $\mathrm{H}$. Positive and negative effects of family involvement on work-related burnout. J Vocat Behav2008; 73(3): 387-96.

9- Kahn JH, Schneider KT, Jenkins-Henkelman TM, Moyle LL. Emotional social support and job burnout among high-school teachers: is it all due to dispositional affectivity?. J Organ Behav2006; 27(6): 793-807.

10- Roche M, Haar JM. Leaders life aspirations and job burnout: a self-determination theory approach. Leadership \& Organization Development Journal2013; 34(6): 515-31.

11- Swider BW, Zimmerman RD. Born to burnout: a meta-analytic path model of personality, job burnout, and work outcomes. J Vocat Behav2010; 76(3): 487506.

12- Shirom A. Job-related burnout: A review. In Quick JC, Tetrick LE, eds. Handbook of occupational health psychology. Washington, DC, US: American psychological association; 2003. pp. 245-64.

13- Schaufeli WB, Bakker AB, Van Rhenen W. How changes in job demands and resources predict burnout, work engagement and sickness absenteeism. J Organ Behav2009; 30(7): 893-917.

14- Fernet C, Gagne M, Austin S. When does quality of relationships with coworkers predict burnout over time? The moderating role of work motivation. J Organ Behav2010; 31(8): 1163-80.

15- Trachtenberg J. Work-home conflict and domestic violence. Dissertation Abstracts International: Section A. Humanities and Social Sciences2008; 68: 18- 32.

16- Roos E, Lahelma E, Rahkonen O. Work-family conflicts and drinking behaviours among employed women and men. Drug Alcohol Depend2006; 83(1): 49-56.

17-Roos E, Sarlio-Lähteenkorva S, Lallukka T, Lahelma E. Associations of work-family conflicts with food habits and physical activity. Public Health Nutr2007; 10(3): 222-9.

18- Grice MM, Feda D, McGovern P, Alexander BH, McCaffrey D, Ukestad L. Giving birth and returning to work: the impact of work-family conflict on women's health after childbirth. Ann Epidemiol2007; 17(10): 791-8. 19- Frone MR, Barnes GM, Farrell MP. Relationship of 
work-family conflict to substance use among employed mothers: The role of negative affect. $J$ Marriage Fam 1994; 56(4):1019-30.

20- Mauno S, Kinnunen U. The effects of job stressors on marital satisfaction in finnish dual-earner couples. $J$ Organ Behav1999; 20(6): 879-96.

21- Lambert EG, Hogan NL, Camp SD, Ventura LA. The impact of work- family conflict on correctional staff: A preliminary study. Criminol \& Crim Just2006; 6(4): 37187.

22- Boyar S, Mosley DC. The relationship between core self-evaluations and work and family satisfaction: The mediating role of Job burnout and facilitation. J Vocat Behav2007; 71(2): 265-81.

23- Shakerinia I, Mohammadpour M. Relationship between job stress and resiliency with occupational burnout among nurses. Journal of Kermanshah University of Medical Sciences2010; 14(2): 161-9.

24- Ghobaribonab B, Khazayi M, Alizade H, Toofi Z. Examine predictors of burnout (teachers of retarded children and normal in the city of Birjand). Journal of Psychotherapy Cute2003; 4: 124-47.

25- Maslach C, Leiter MP. Reversing burnout how to rekindle your passion for your work. Stanford Social Innovation Review2005; 3(4): 41-9.

26- Robbins SP, Judge T. Essentials of organizational behavior. New Jersey, US: Prentice Hall; 2007.

27- Maslach C, Jackson SE. Burnout in health professions: a social psychological analysis. In: Sanders GS, Suls J, eds. Social psychology of health and illness. Hillsdale: Erlbanm; 1982. pp: 227-51.

28- Smith PC, Kendall LM, Hulin CL. The measurement of satisfaction in work and retirement: A strategy for the study of attitudes. Oxford, England: Rand Mcnally; 1969.

29- Dunham RB, Smith FJ, Blackburn RS. Validation of the index of organizational reactions with the JDI, the MSQ, and faces scales. Academy of Management Journal1977; 20(3): 420-32.

30-Adriaenssens J, De Gucht V, Maes S. Determinants and prevalence of burnout in emergency nurses: a systematic review of 25 years of research. Int $J$ Nurs Stud2015; 52(2): 649-61.

31- Barrett L, Yates P. Oncology/haematology nurses: a study of job satisfaction, burnout, and intention to leave the specialty. Aust Health Rev2002; 25(3): 109-21.

32-Jorgensen Dick M. Burnout in nurse faculty: relationships with management style, collegial support, and work load in collegiate programs. J Prof Nurs 1986; 2(4): 252-60.

33- López Franco M, Rodríguez Núñez A, Fernández Sanmartín M, Marcos Alonso S, Martinón Torres F, Martinón Sánchez JM. Burnout syndrome among health workers in pediatrics. An Pediatr (Barc)2005; 62(3): 248-51.

\footnotetext{
Copyright(C) 2016 ASP Ins. This open-access article is published under the terms of the Creative Commons Attribution-NonCommercial 4.0 International License which permits Share (copy and redistribute the material in any medium or format) and Adapt (remix, transform, and build upon the material) under the Attribution-NonCommercial terms.
} 